\title{
Fe y cultura en las reflexiones teológicas de Comblin, Scannone y Trigo: convergencias y diferencias
}

\author{
RAFAEL NiÑO DE ZEPEDA GUMUCIO \\ Universidad Católica Silva Henríquez (Chile) \\ rninodez@ucsh.cl
}

\begin{abstract}
Resumen
El propósito de este artículo es identificar convergencias y diferencias acerca de la relación fe-cultura en las reflexiones de tres teólogos latinoamericanos, quienes representan, de alguna manera, tres grandes líneas teológicas de los últimos cincuenta años. Los tres autores convergen en su interés por conocer e interpretar la cultura latinoamericana y su relación con el Evangelio. Pero divergen en una variedad de aspectos. Esto se puede apreciar por los conceptos, o categorías, utilizados: la idea de la liberación sociocultural como implicación de la misma evangelización (Comblin), la idea de una síntesis entre las culturas originarias y la evangelización ibérica (Scannone), y la idea que valora la realidad multiétnica y pluricultural de nuestro subcontinente (Trigo). Los tres autores estudiados muestran más diversidad que convergencia, e incluso, oposición entre sus planteamientos y opciones pastorales.
\end{abstract}

Palabras claves: Cultura, evangelización, Latinoamérica, liberación, inculturación.

\section{Faith and culture in the theological thought of Comblin, Scannone and Trigo: convergences and differences}

\begin{abstract}
The purpose of this article is to identify similarities and differences about the relationship between faith and culture in the reflections of three Latin American theologians who represent, somehow, three great theological lines cin-account recent years. The three authors converge in their interest to know and interpret Latin American culture and its relationship with the Gospel. But they diverge in a variety of ways. This can be seen by concepts, or categories, used the idea of cultural liberation as involvement in the same evangelization (Comblin), the idea of a synthesis between the native cultures and the Iberian evangelization (Scannone), and the idea that values the multiethnic and multicultural reality of our continent (Wheat). The three authors studied show more diversity than convergence, and even opposition between his approach and pastoral options.
\end{abstract}

Key words: Culture, evangelization, Latin America, liberation, inculturation.

Doctor en Teología. Docente en la Facultad de Ciencias Religiosas y Filosofía de la Universidad Católica Silva Henríquez y encargado del Centro de Estudios en Fe y Cultura. Últimas publicaciones: La ambigüedad de la técnica. Comprensión de la técnica en la perspectiva de su ambigüedad, en la teología de la mediación de Paul Tillich (2013); El concepto de lo demoníaco en el pensamiento de P. Tillich y su raíz en J. Boebme, F.W. Schelling y el misticismo luterano (2014).

El presente artículo es producto del Proyecto Impulso 2014 (UCSH): "Fe y cultura en América Latina. Análisis textual sobre la relación de convergencia y divergencias en la interpretación de la filosofía y la teología sobre la relación entre la fe y la cultura en Latinoamérica, desde el Concilio Vaticano II en adelante". 


\section{Introducción}

El presente artículo tiene como propósito identificar las convergencias y diferencias entre las ideas principales elaboradas por tres teólogos latinoamericanos: J. Comblin, J.C. Scannone y P. Trigo, con respecto a la relación entre fe y cultura en Latinoamérica. Los tres teólogos seleccionados representan, a mi juicio, tres diferentes líneas de desarrollo con respecto a la relación entre la fe y la cultura dentro del período de la teología latinoamericana post conciliar, más precisamente, desde la denominada propiamente teología de la liberación hasta el presente.

A modo de introducción, para este artículo, presento en forma muy general y resumida las grandes líneas de desarrollo teológico de la reflexión fe-cultura en la teología latinoamericana, de manera de justificar la elección de los tres autores escogidos:

Las posturas de los teólogos latinoamericanos en el período postconciliar emergen en un contexto muy especial, tanto eclesial como social y político. La década de los 60 está marcada por los movimientos sociales, el despertar de la conciencia latinoamericana, la expansión del sistema capitalista, entre otros factores, además de los profundos cambios producidos por el Concilio Vaticano II y sus efectos en la Iglesia latinoamericana. Las reflexiones teológicas latinoamericanas de este período deben ser entendidas en este contexto social y eclesial, y en íntima conexión y diálogo con las orientaciones pastorales de los obispos en las sucesivas asambleas de la Conferencia del Episcopado Latinoamericano. En efecto, en el contexto de la Conferencia de Medellín, realizada en 1968 (CELAM, 1971) existieron pioneros que trataron de pensar teológicamente la realidad latinoamericana, entre los que hay que mencionar a Gustavo Gutiérrez, Juan Luis Segundo, Joseph Comblin, Lucio Gera y otros. Pero Gutiérrez es quien plantea primeramente la comprensión global explícita de la teología de la liberación. Estas intuiciones originales van a tomar cuerpo, en 1971, en su libro Teología de la liberación. Perspectivas. En este primer período se toca el tema de la cultura, pero subordinado a categorías más relevantes como lo económico y lo político.

En segundo lugar cabe destacar la línea de reflexión argentina, que ubica en su centro el tema de la cultura. Se trata de una corriente de la teología de la liberación que se la ha denominado como teología del pueblo. Algunos se refieren a ella como la teología argentina del pueblo (Scannone, 2012: 205). Su origen se encuentra en una iniciativa de la Conferencia Episcopal Argentina (COEPAL), en 1966, formada por obispos, teólogos y pastoralistas, cuya finalidad era plantear un plan nacional de pastoral según el espíritu del Vaticano II. La formaban obispos, pastoralistas, religiosos, y teólogos. Aquí destacan como fundadores Lucio Gera, Ra- 
fael Tello, Justino O'Farrel, Guillermo Sáenz, y Gerardo Farrel, entre otros. Se destaca, por su trascendencia Lucio Gera. En una segunda etapa de su desarrollo hay que ubicar a Pablo Sudar y especialmente a Juan Carlos Scannone, quien en su libro Evangelización, cultura y Teologia (1990), resume su línea de pensamiento, centrada en la idea de la existencia de un ethos cultural propio del pueblo latinoamericano cuyo núcleo está determinado por la sabiduría popular cristiana, que es fruto de la evangelización. Es esta sabiduría popular la que podría constituirse como una mediación para la inteligencia inculturada de la fe. En una tercera etapa se puede ubicar a Carlos Galli.

En la actualidad - ya entrado el presente siglo- nos encontramos con un panorama más bien disperso al respecto. No obstante, se puede esbozar algunas líneas de pensamiento. Por un lado se pueden identificar una especie de postura que apunta a una recepción positiva de lo que se denomina como cultura posmoderna y una bienvenida a la interculturalidad. En este sentido podemos identificar los trabajos del teólogo venezolano Pedro Trigo. En su libro Relaciones Humanizadoras, publicado en 2013, habla de un imaginario alternativo, incluyendo en este término el concepto de cultura y de la utopía. Este nuevo imaginario invita a una nueva relación entre fe y la cultura posmoderna en términos de recuperar otras dimensiones humanas que no entran en el contrato social moderno. En esta misma línea de valoración positiva del nuevo horizonte cultural se encuentran los teólogos Eugenio Toland (2013) y Alberto Roldán (2000). Para el primero, la cultura posmoderna ofrece más oportunidades que obstáculos a la misión cristiana. Es necesario, eso sí, utilizar una narrativa cristiana con lenguaje fresco. El segundo invita a plantear una nueva reflexión teológica ante el reto del primado de la experiencia y la realidad del pluralismo cultural. Otro teólogo que podemos mencionar aquí es Sergio Silva G., él se refiere específicamente a la «tendencia autodestructiva de la modernidad» (Silva, 1992: 71) manifestada, por ejemplo, en el predominio de la razón técnica que erige el método científico en única vía de acceso a la realidad, la cual puede ser superada por medio de lo que se puede llamar como un ethos del Evangelio, que se puede expresar en tres valores: la teonomía, la solidaridad y la trascendencia. Por último, caben también en esta tercera línea aquellas reflexiones que se enmarcan dentro de lo que se podría denominar como teología de la interculturalidad. Se trata de establecer un diálogo entre la fe y las diversas culturas, rechazando la hegemonía de una cultura sobre las demás. En esta línea hay que mencionar a Raúl Fornet-Betancourt (2007), Alberto Roldán (2000), Diego Irarrázabal (2013), Ronaldo Muñoz (2009), entre otros. 
Ahora bien, de estas tres grandes líneas teológicas, he seleccionado a tres autores respectivamente. Estos son Joseph Comblin, Juan Carlos Scannone y Pedro Trigo. De cada uno de estos autores he seleccionado una publicación, sea este artículo de revista o parte de libro, con la excepción de Scannone, de quien he seleccionado dos publicaciones puesto que ambos se complementan para captar mejor el pensamiento de este teólogo argentino. La razón para haber seleccionado tal o cual texto obedece a los criterios de originalidad y representatividad, vale decir, el texto que mejor expresa el pensamiento original de estos autores con respecto a nuestro tema y su cualidad de ser representativos de la corriente teológica en la cual son ubicados. Así pues, de José Comblin el texto elegido es "Evangelización de la cultura en América Latina", artículo publicado en la revista Persona y Sociedad (1988) N² 2, pp. 139-154. Entre los escritos de Juan Carlos Scannone escogí los artículos "Ethos y sociedad en América latina: perspectivas sistemático-pastorales" y "Evangelización de la cultura y religiosidad popular latinoamericana", ambos artículos publicados en el libro Evangelización, cultura y teología, pp. 77-93, y pp. 126-137 respectivamente. Por último, del teólogo Pedro Trigo escogí el capítulo VI de su libro Relaciones Humanizadoras. Un imaginario alternativo, titulado "Construir una América latina pluricultural para contribuir proactivamente a una mundialización alternativa".

El método utilizado consistió en la lectura de los textos empleando el programa computacional Atlas $\mathrm{Ti}$, creado fundamentalmente para la investigación cualitativa denominada Teoría Fundamentada (Grounded Theory) (Vasilachis de Gialdino, 2006). Por este medio pretendí dejar hablar a los textos mismos. La intención fue leer los textos utilizando este software de forma análoga a la utilización de una lente a través la cual traté de identificar sus conceptos (categorías) principales. Traté de leer los textos desprejuiciadamente, dejándome guiar ayudado por el instrumento computacional, para descubrir las categorías que estructuran el texto y establecer sus relaciones.

La investigación se llevó a cabo mediante tres pasos metodológicos consecutivos. Primero, la lectura de los textos a través del programa Atlas Ti, con el fin de identificar las categorías principales que estructuran el texto. Este procedimiento es denominado codificación. El segundo paso fue la identificación de las líneas fundamentales de pensamiento que surgen de los resultados de la codificación. El tercer paso fue una interpretación de los cuatro textos en su conjunto, identificando las convergencias y las diferencias con respecto a nuestro tema.

A continuación daré a conocer el resultado del análisis de los escritos estudiados, siguiendo los pasos metodológicos recién señalados. A saber, primero mostraré el resultado de la codificación, identificando las catego- 
rías principales encontradas y las veces que aparecen en el texto. En seguida, basándome en tales categorías y sus relaciones identificaré e interpretaré las líneas de pensamiento centrales de cada uno de los tres autores y sus posibles relaciones. Finalmente, en la tercera parte, presentaré algunas reflexiones conclusivas, destacando las convergencias y diferencias entre los autores con respecto al tratamiento del tema de la relación fe y cultura.

\section{Análisis de los textos}

\subsection{Joseph Comblin, "Evangelización de la cultura en América Latina"}

En este artículo Comblin destaca las siguientes categorías: cultura, cultura latinoamericana, cultura-organización política, cultural-trabajo, evangelización de la cultura, humanización, invasión occidental, liberación de la cultura, relación fe y cultura ${ }^{1}$.

Sobre la base del análisis de estas categorías y de sus relaciones, podemos identificar un relato que refleja una interpretación con características propias de la relación entre fe y cultura. En primer lugar, hay que decir que en el artículo Comblin comienza sus reflexiones sobre la cultura de manera muy apegada al Concilio Vaticano II (Constitución Gaudium et Spes) y a la Exhortación Evangelii Nuntiandi. En efecto, este escrito de Comblin refleja el impacto que Pablo VI produjo con su idea-fuerza de la evangelización de la cultura. El mismo Papa decía «lo que importa es evangelizar la cultura y las culturas del hombre» (Pablo VI, 1995: 20), entendiendo por la evangelización «no de una manera decorativa, como un barniz superficial sino de una manera vital, en profundidad y hasta sus mismas raíces» (Pablo VI, 1995: 20). En cuanto al concepto mismo de cultura, nuestro autor se centra en Gaudium et Spes:

Con la expresión "cultura", en general, se indica todo aquello con lo que el hombre afina y desarrolla sus innumerables cualidades espirituales y corporales; procura someter al mismo orbe terrestre con su conocimiento y trabajo; hace más humana la vida social, tanto en la familia como en toda la sociedad civil, mediante el progreso de las costumbres e instituciones; finalmente a través del tiempo formula, comunica y conserva en sus obras

\footnotetext{
1 Las veces en que se mencionan estas categorías son: cultura latinoamericana, 15; cultura, 7; evangelización de la cultura, 6; cultural-trabajo, 5; relación fe y cultura, 5; liberación de la cultura, 4; invasión occidental, 3; cultura-organización política, 1; humanización, 1.
} 
grandes experiencias espirituales y aspiraciones para que sirvan de provecho a muchos (Gaudium et Spes: 53).

Como se puede apreciar, se trata de un concepto muy amplio, que abarca tanto la dimensión social como el ámbito de los valores y del sentido, sin caer en el culturalismo.

Con respecto a la relación entre fe y cultura Comblin también hace eco de los principios planteados por Gaudium et Spes y Evangelii Nuntiandi. A saber, que la Iglesia y el evangelio no están ligados a ninguna cultura más que a otra, sin perjuicio de que la Iglesia se siente profundamente solidaria con el género humano y su historia; también que el cristianismo lleva a la cultura a una plenitud que ellos no pueden alcanzar por sí mismos (Comblin, 1988: 143-147). El cristianismo libera del mal a las culturas, porque el mundo se encuentra esclavizado bajo la servidumbre del pecado, pero liberado por Cristo (Gaudium et Spes: 2). Por tanto, la cultura y el mundo son ambiguos y solo Cristo los puede liberar. Pero Comblin no se queda en los principios generales, sino que plantea una relación activa y específica entre la fe y la cultura. En este sentido, y siguiendo Evangelii Nuntiandi, esta relación es la evangelización: «El aporte nuevo y específico del cristianismo al dinamismo de la cultura se llama evangelización» (Comblin, 1988: 147). Pues evangelizar la cultura significa que el esfuerzo evangelizador no queda en lo superficial, decorativo, sino que llega hasta las raíces del hombre y la sociedad.

Luego de este punto de partida en los documentos magisteriales, nuestro autor continúa con reflexiones más propias. En primer lugar, llama la atención la relación que establece entre cultura, trabajo y organización política. En efecto, Comblin entiende la cultura como un régimen de trabajo «La cultura es un régimen de trabajo: en América Latina el antiguo régimen de trabajo ha sido destruido por la conquista; el régimen de trabajo ha sido impuesto por las conquistas sucesivas de la economía occidental» (Comblin, 1988: 148). La cultura y el trabajo no pueden separarse. La cultura es determinada por el trabajo. La distribución del tipo de trabajo y su significado son el fundamento de la cultura y la sociedad. Dependiendo si el trabajo es entendido como un mero medio de producción, o como medio de humanización se determinan evidentemente dos tipos distintos de sociedad y cultura. Las sucesivas invasiones acontecidas en América Latina, con sus formas de concebir el trabajo humano, han determinado un tipo de sociedad y culturas desintegradas y estratificadas.

El segundo término relacionado con la cultura, es la organización política (Comblin, 1988: 148). El hecho que la cultura sea entendida como una organización política, indica el significado social estructural de la 
cultura. La cultura construye algo objetivo, visible: la estructura de poder de la sociedad. La estructura-poder ya existía en América prehispánica, pero al igual que el régimen de trabajo, esta estructura fue destruida y a cambio se impuso una estructura foránea, a través de tres invasiones sucesivas (Comblin, 1988: 149-151).

Pero nuestro autor va más allá, tiene una visión crítica con respecto a la creencia en una síntesis cultural latinoamericana que haya dejado un sustrato cultural evangelizado. Al contrario, sostiene que «no hubo síntesis armoniosa espontánea, con posibilidades iguales, no hubo diálogo entre la cultura de los conquistadores y la cultura de los indígenas de América o de los esclavos importados desde África» (Comblin, 1988: 149). Aún más, habla del mito de la cultura latinoamericana y del submito de la religiosidad popular latinoamericana (Comblin, 1988: 149). Así como hay una multitud de culturas, también hay múltiples religiones, heterogéneas y marcadas por las conquistas: la religión de los indios, de los negros, la religión de los conquistadores, etc. (Comblin, 1988: 149). En efecto, en la primera invasión, o conquista de la cultura occidental, la que siguió el descubrimiento de América en 1492, los conquistadores impusieron por la violencia una cultura foránea y una marginalización de la cultura local; la segunda invasión consistió en la europeización del siglo XIX, pues las nuevas naciones independientes no buscaron la promoción de los indígenas y de los esclavos, sino el progreso económico por medio de la integración al sistema económico europeo, junto con una masiva inmigración europea, especialmente en el sur del subcontinente; por último, la tercera invasión cultural consistió en el proceso de integración dentro de la economía occidental dominante, liderada por Estados Unidos. En este proceso las economías nacionales se vincularon con las empresas multinacionales, teniendo como consecuencia la proletarización del campesinado, las masas de cesantes, etc. Pues bien, en este triple proceso de conquista, o invasión cultural occidental, nunca hubo una síntesis armoniosa; no hubo diálogo (Comblin, 1988: 149), al contrario, las tres invasiones distorsionaron la cultura (Comblin, 1988: 153), y lo que siguió fue un conjunto de culturas heterogéneas y yuxtapuestas.

Es necesario, por último, completar la reflexión de Comblin con el concepto de la liberación. Este término, que, como sabemos, determinó el título de esta corriente de la teología latinoamericana, no deja de estar presente en el pensamiento sobre la cultura y la fe. En efecto, según nuestro autor, la cultura latinoamericana debe ser liberada de sus propias distorsiones. Se trata de un cambio de línea, de manera que las culturas marginadas deben basarse en un trabajo eficiente que los haga progresar efectivamente, y también la cultura de los ricos debe ser liberada de su vanidad y sinsentido. Pero este concepto de liberación no está desligada 
de la evangelización. Pues, «la evangelización es una palabra, un mensaje para una cultura cuyo desafío es la liberación» (Comblin, 1988: 154).

\subsection{Juan Carlos Scannone: “Ethos y sociedad en América latina: perspectivas sistemático-pastorales" y "Evangelización de la cultu- ra y religiosidad popular latinoamericana"}

En los dos artículos escogidos de este teólogo argentino predominan las siguientes categorías: cultura latinoamericana, cultura-trabajo, ethos cultural, evangelización de la cultura, religiosidad popular, frutos de la evangelización, inculturación, núcleo ético-sapiencial, pueblo, sabiduría popular y síntesis vitales ${ }^{2}$.

Como está dicho anteriormente, Scannone es uno de los máximos exponentes de la denominada teología argentina del pueblo. Que sea, o no sea, una corriente dentro de esta última es asunto de opinión. Hay quienes la ubican como una corriente dentro de la teología de la liberación, como G. Gutiérrez; y otros como una corriente dentro de la teología latinoamericana, pero no como parte de la teología de la liberación. En independencia de estas dos formas de comprenderla, es inevitable identificar algunos aspectos básicos comunes con la teología de la liberación, tales como la preocupación por los procesos latinoamericanos de subjetivación de los pobres, o del pueblo, en el camino de su liberación, su construcción de síntesis vitales, y la referencia al trabajo como base de la cultura. En esta línea básica común con J. Comblin en cuanto representante de la teología de la liberación, llama la atención la referencia de ambos autores al Concilio Vaticano II y Evangelii Nuntiandi, en cuanto significan puntos de partida para una renovada relación entre el Evangelio y el mundo, o, dicho de otra manera, entre fe y cultura. Pero Scannone, a diferencia de Comblin, hace continua referencia a los documentos de Medellín (CELAM, 1971) y Puebla (CELAM, 1985). Es notable la sintonía del pensamiento de Scannone con los documentos episcopales latinoamericanos, especialmente Puebla. No es, pues, muy aventurado afirmar la influencia directa de la teología argentina del pueblo en la elaboración de los documentos de Puebla. Las categorías de religiosidad popular, síntesis vital y frutos de la evangelización, entre otras, tan utilizados por Scannone están en plena sintonía con el documento emanado de la reunión en Puebla.

\footnotetext{
2 Las veces en que se mencionan estas categorías son: Ethos cultural, 13; evangelización de la cultura, 8; cultura-trabajo, 6; religiosidad popular, 5; cultura latinoamericana, 4; síntesis vital, 4; frutos de la evangelización, 3; sabiduría popular, 3; inculturación, 2; núcleo ético-sapiencial, 2; pueblo, 2.
} 
Concentrándonos ahora en la originalidad de Scannone, esta se deja ver por la utilización de un conjunto de conceptos íntimamente relacionados entre sí, de tal manera que de su interrelación emana un pensamiento original. Estos conceptos, o categorías, son: ethos cultural, religiosidad popular, síntesis vitales, frutos de la evangelización, sabiduría popular, núcleo ético-sapiencial y pueblo. Las cuales conforman una línea dentro de la teología latinoamericana que privilegia la unidad por sobre el conflicto (Scannone, 1990: 69). Para esta línea «...existe una cultura latinoamericana, aunque no uniforme ni homogénea ni exenta de fuertes contradicciones, pero con suficiente unidad histórica y líneas nucleares comunes, como para que se le pueda asignar una unidad plural o analógica» (Scannone, 1990: 69).

Desarrollaremos a continuación estas ideas. En primer lugar, la categoría más utilizada por Scannone es ethos cultural. Mediante este término nuestro autor maneja un concepto de cultura en la perspectiva de los valores vividos y transmitidos comunitariamente. El ethos es entendido como «el modo particular de vivir y habitar éticamente el mundo que tiene una comunidad histórica (un pueblo, una clase social, una comunidad religiosa, etc.) en cuanto tal en su historia» (Scannone, 1990: 77). Nuestro autor, entonces, entiende por ethos no solo el momento ético que orienta la acción de una comunidad determinada, sino también el carácter peculiar de los principios y valores que conforman un estilo de vida histórica determinada que implica un modo particular de relacionarse con el sentido último, con los otros hombres y con la naturaleza (Scannone, 1990: 78). A esta segunda comprensión es a lo que apunta el término ethos cultural, es decir, el conjunto de valores y desvalores, modos de relacionarse con los demás y la naturaleza, sabiduría de la vida y relación con el sentido último, con lo religioso. Y el sujeto de este ethos cultural es el pueblo, entendiendo este último como el pueblo-nación, como la unidad plural de una cultura común.

A partir de esta comprensión de la cultura, Scannone afirma la existencia de un sustrato cultural latinoamericano, producto de una síntesis vital entre las culturas originarias y la evangelización ibérica. El Evangelio ha influido en la formación del ethos cultural latinoamericano fundamental, caracterizado por un núcleo ético-sapiencial con un profundo sentido cristiano del hombre y de la vida (Scannone, 1990: 85).

Predomina, entonces, la idea de la unidad cultural latinoamericana antes que la desintegración y distorsión. Pues sin desconocer la variedad de culturas, Scannone reconoce la existencia de un sustrato cultural común, un núcleo cultural ético-sapiencial evangelizado que ya da frutos evangelizadores. En el siguiente extracto, y en sintonía con Puebla, podemos encontrar esta idea fundamental formulada por nuestro autor: 
la cultura latinoamericana surgida del encuentro de las culturas ibéricas con las indígenas, al que luego se fueron sumando en distintas partes los aportes de los africanos y de la inmigración posterior, es, en su base, una cultura sellada por la fe, es decir, que ha sido evangelizada en su núcleo más íntimo de valores, aunque tenga grandes deficiencias y, como todo lo humano, necesita de una continua evangelización (Scannone, 1990: 130)

Tal núcleo ético-sapiencial se manifiesta privilegiadamente en la religiosidad popular. Esta religiosidad popular, o religión del pueblo, o piedad popular, es, como se afirma en Puebla «el conjunto de hondas creencias selladas por Dios, de las actitudes básicas que de esas convicciones derivan y las expresiones que las manifiestan» (CELAM, 1985: 444). Scannone sostiene una alta valoración por la religiosidad popular, pues él la asume no como objeto de evangelización, sino como una fuerza evangelizadora, porque es manifestación de un núcleo cultural ya evangelizado que produce frutos de evangelización. No solo se encuentran en él las semillas del Verbo, sino ya los frutos del Verbo. Y, por último, frente al desafío de la nueva cultura universal adveniente propio del fenómeno de la globalización, Scannone asume esta religiosidad popular como el punto de partida para la construcción de una síntesis vital (Scannone, 1990: 137).

\subsection{Pedro Trigo, "Construir una América Latina pluricultural para contribuir proactivamente a una mundialización alternativa"}

En este capítulo del libro Relaciones Humanizadoras. Un imaginario alternativo, su autor, el teólogo venezolano Pedro Trigo releva las siguientes categorías: etnias y culturas, multiétnico y pluricultural, cultura occidental dominante, buena nueva, globalización, voluntad de Dios, inculturación ${ }^{3}$.

Trigo comienza su capítulo presentando una tesis: que América Latina está entrando en su tercera época histórica. En efecto, Trigo distingue tres épocas. La primera es denominada amerindia, y la segunda peninsular. La nueva época en la que estamos entrando es la tercera, aunque, de hecho nos encontramos aún en la última parte de la segunda época porque se mantiene el paradigma occidental (Trigo, 2013: 284285). Esta tercera época se abre porque un número cada vez mayor de sujetos sociales emergentes están exigiendo que América Latina asuma una nueva configuración que la capacitará para intervenir eficazmente para cambiar el proceso de la globalización, en alianza con otras fuerzas

\footnotetext{
3 Las veces en que se mencionan estas categorías son: multiétnico y pluricultural, 19; etnias y culturas, 11; inculturación, 4; occidentalización homogeneizadora, 3; globalización, 2; voluntad de Dios, 2; buena nueva, 1.
} 
de las diversas regiones (Trigo, 2013: 283). ¿Cuál va a ser esta nueva configuración? La respuesta la va a desarrollar a lo largo del capítulo. Pero quiero comenzar por clarificar en qué consiste, según nuestro autor, el nuevo contexto y los nuevos sujetos de tal configuración.

En cuanto al contexto, este subcontinente está entrando en una nueva época histórica cuyos desafíos están planteados por la dirección dominante que comanda el proceso de la globalización. El problema en Latinoamérica no se plantea ahora como la relación de dependencia de los países pobres con respecto al centro de poder político-económico identificado principalmente con Estados Unidos y sus aliados, sino que el problema es planteado en términos netamente culturales. Esto se puede apreciar en la siguiente cita:

Se lucha porque la cultura occidental dominante dé lugar a las demás culturas, no solamente para que se expresen como hasta hoy en sus ámbitos particulares y subalternos, sino para que esas culturas impriman su sello en el continente como tal, conjuntamente con la occidental: en la configuración institucional, en el ambiente público, en el horizonte compartido, en el modo de relacionarse (Trigo, 2013: 288)

La amenaza para América Latina es, entonces, cultural. La globalización constituye una amenaza en cuanto implica una occidentalización homogeneizadora (Trigo, 2013: 292). Esta amenaza, aunque viene de fuera de las fronteras de los países latinoamericanos, también se hace presente al interior de nuestras sociedades por medio de lo que Trigo denomina como los occidentales, quienes continúan imponiendo despóticamente su cultura occidental y reaccionando viceralmente contra el intento de los pueblos de constituirse como sujetos multiculturales.

En este nuevo horizonte epocal, nuestro autor plantea el nuevo desafío para nuestro subcontinente de la siguiente manera:

Porque el reto histórico es consolidarnos como región multiétnica y pluricultural en estado de justicia, emulación y solidaridad, para así poder hacer frente al desafío de entrar como región específica en el proceso de configurar una mundialización policéntrica y simbiótica en la que los frutos de la última revolución tecnológica den de sí armónicamente para el bien de todos en un proyecto compartido y sustentable (Trigo, 2013: 293-294).

Quienes están liderando este reto histórico son los sujetos sociales emergentes, constituidos por un creciente número de personas de etnias no occidentales y de culturas indígenas, afrolatinoamericanas, campesinas y suburbanas que luchan por adquirir los bienes civilizatorios y culturales de occidente mundializado, pero no para blanquearse u occidentalizarse, 
sino para ser lo que son. Ellos se están volviendo a descubrir a sí mismos como seres históricos, «no como sobrevivientes del pasado -pueblos testimonio, en la terminología de Darcy Ribeiro- sino como seres con historia y con capacidad de seguir haciéndola» (Trigo, 2013: 287).

A partir de esta nueva conciencia y nuevos desafíos, se comprende la utilización de nuevas categorías que se encuentran presentes en el texto de Trigo. En efecto, las categorías multiétnico y pluricultural, y etnias y culturas son las dos categorías predominantes. Lo multiétnico y pluricultural reemplaza en importancia a la categoría nucleo ético-sapiencial tan utilizado por Scannone. Y, por otro lado, la categoría etnias y culturas plantea un concepto de cultura ligado al concepto de etnia. La diversidad de culturas se identifica con la diversidad de etnias. Ya no se habla de un ethos cultural como sustrato latinoamericano común producto de una síntesis cultural, sino al contrario, se releva y valora la diversidad.

Otra categoría que se encuentra presente en este texto es la inculturación, entendiendo esta última como la idea de inculturar el Evangelio en cada cultura en forma particular. Pues «el reconocimiento de las diversas culturas lleva consigo la inculturación del Evangelio a cada una de ellas. El requisito para llevarla a cabo es la desabsolutización del catolicismo criollo» (Trigo, 2013: 316). Pero para esta tarea la institución eclesiástica criolla no está capacitada, porque la inculturación se podrá hacer solo desde dentro, «solo cristianos de cada cultura podrán llevar a cabo la inculturación del cristianismo en ellas» (Trigo, 2013: 317).

Por último, llama la atención la utilización de las categorías voluntad de Dios y buena nueva, y, al mismo tiempo la ausencia de la categoría evangelización de la cultura. Se podría decir que las dos primeras categorías reemplazan a la categoría evangelización de la cultura. Pues el desafío para el cristianismo de hoy no es evangelizar la cultura, sino secundar el movimiento por la pluri-culturalidad, y con esto hacer la voluntad de Dios. Esta es ahora la buena nueva (Trigo, 2013: 315-316). Esto lo podemos apreciar en la siguiente cita:

como cristianos no podemos menos que decir que este movimiento, que reivindica el reconocimiento de las diversas identidades y por tanto la relativización de la cultura occidental y de los occidentales, es voluntad de Dios y que, por tanto, quien se opone a él, se opone a Dios y quien lo secunda hace la obra de Dios (Trigo, 2013: 312).

En este contexto, la Iglesia en su conjunto está llamada a participar de este movimiento de reconocimiento multiétnico y pluricultural. Trigo concluye este escrito decidoramente en este sentido: 
Solo una Iglesia que se meta de lleno en este fecundo Pentecostés, podrá contribuir desde dentro a que efectivamente la región, que es multiétnica, exprese en sus instituciones y en sus símbolos su carácter pluricultural, lo que constituye un signo de los tiempos y es claramente voluntad de Dios (Trigo, 2013: 320).

\section{Análisis comparativo}

Del análisis de los textos de los tres teólogos podemos identificar algunas relaciones: convergencias y diferencias entre las ideas y planteamientos de los tres autores

\subsection{Convergencias}

Veremos, en los párrafos siguientes, que las diferencias sobresalen, por mucho, en comparación con las convergencias entre los tres autores estudiados. En efecto, en este punto identificaré solo tres. Sin embargo, más allá del número, quiero hacer notar que los puntos en que convergen constituyen el fundamento desde donde realizan sus reflexiones teológicas. Los tres autores comparten el punto de partida y el interés teológico básico por reflexionar sobre la fe y la cultura en América Latina.

El primer punto de confluencia es que los tres autores continúan el impulso iniciado por el Concilio Vaticano II y Evangelii Nuntiandi por mirar la cultura actual con una actitud dialogante con la fe cristiana; reconociendo las luces y sombras de la cultura moderna, y mirándola como objeto de la misma evangelización.

El segundo punto de convergencia es una continuación del punto anterior, a saber, el interés por la cultura de hoy, pero dirigido en concreto a la cultura latinoamericana. Los tres autores dirigen su mirada teológica a la cultura del subcontinente latinoamericano, se preguntan ¿cómo es? ¿Cuáles son sus expresiones? ¿Cuál ha sido la influencia de la evangelización en las culturas originarias?, etc.

Un tercer aspecto común en nuestros tres teólogos es la conciencia de estar entrando en una nueva situación cultural, un encuentro con una cultura que traspasa las fronteras nacionales. Una nueva cultura global, marcada por las nuevas tecnologías, con sus valores y desvalores. Los tres autores se plantean, de una u otra manera, las preguntas: ¿cómo ser creyente en este nuevo contexto?¿cómo anunciar el evangelio?¿qué nos pide Dios ahora? 


\subsection{Diferencias}

Las diferentes maneras de comprender la cultura latinoamericana y de establecer su relación con la fe cristiana son muy marcadas entre los textos analizados. En seguida presento las diferencias más importantes.

\subsubsection{Concepto de cultura}

De los tres autores analizados saltan a la vista tres conceptos distintos de cultura. Para Comblin la cultura se relaciona con el concepto de trabajo, comprendiendo este último como productor de sistemas sociales-políticos. «La cultura es un régimen de trabajo [...] La cultura es una organización política» (Comblin, 1988: 148). Las diversas invasiones culturales han creado sistemas de trabajo, de tal manera que se han construido diversos sistemas de relaciones, pues «el régimen de trabajo ha sido impuesto por las conquistas sucesivas de la economía occidental» (Comblin, 1988: 148). Primeramente la invasión ibérica destruyó el sistema de trabajo de las culturas originarias. La invasión occidental estableció un sistema de relaciones subordinada a la productividad económica. La cultura para Comblin significa, entonces, el sistema social externo producto de las relaciones laborales.

Para Scannone, en cambio, la cultura se relaciona con el concepto de ethos. Entendiendo este último como los valores, los desvalores y el modo de relacionarse entre las personas y con Dios de un pueblo determinado. La cultura entendida así dista mucho del concepto de Comblin, el cual consiste - como vimos anteriormente- en algo externo, visible, en un sistema social producto de la cultura-trabajo. Scannone no desconoce el aspecto visible y social de la cultura, pero apunta a su núcleo, a ese núcleo de valores y de modo de relaciones que es heredado de generación en generación.

Pedro Trigo, por otro lado, pone el acento en lo étnico. Está muy presente en su escrito la categoría étnico-cultural, pero como una categoría netamente conceptual, sin contenido concreto, puesto que al hablar de lo étnico se tiene que referir obligatoriamente a una variedad de etnias. El contenido va a depender, entonces, de cuál etnia sea el sujeto de la cultura.

\subsubsection{Unidad cultural}

Según Comblin no se puede hablar de una cultura latinoamericana, sino de una variedad de culturas yuxtapuestas. Para él la idea de una cultura latinoamericana es un mito. Lo que se constata es más bien un con- 
junto de culturas distorsionadas producto de las sucesivas invasiones. Resalta, nuevamente, el aspecto político-estructural. La variedad de culturas distorsionadas son producto de los efectos de fenómenos políticoeconómico-sociales. Prima una idea negativa sobre la unidad cultural en Latinoamérica.

Scannone sostiene una idea muy distinta a Comblin, incluso se podría decir opuesta. En este teólogo argentino prima la idea de una unidad cultural básica latinoamericana, un sustrato cultural católico producto de una síntesis lograda entre la cultura originaria de los pueblos originarios y la evangelización ibérica. Según esta idea existe un núcleo ético sapiencial evangelizado como un fenómeno generalizado. Este núcleo es altamente valorado. Se podría decir que en Scannone se aprecia una idea optimista frente a la situación cultural latinoamericana, y el desafío de la cultura adveniente globalizada debe enfrentarse desde este núcleo cultural para realizar una nueva síntesis cultural. Este núcleo nos salvaría ante los desvalores de tal cultura globalizada.

En los escritos de Trigo percibimos algo muy distinto a los dos anteriores. Él nunca plantea la idea de una unidad cultural latinoamericana, y menos de un núcleo ético sapiencial evangelizado. Al contrario, se constata la realidad multiétnica y pluricultural, pues la categoría más utilizada es «multiétnico pluricultural», realidad que debe ser respetada y valorada. Incluso para Trigo la solución para América Latina es «constituirse en una región multiétnica y pluricultural» (Trigo, 2013: 309). Se trata de una diversidad cultural proveniente de cuatro grandes sectores: los indígenas, afrolatinoamericanos, campesinos y suburbanos (Trigo, 2013: 318). Se trata, entonces de una multiculturalidad positiva, debe ser bien valorada y preservada.

\subsubsection{La acción de la Iglesia}

Para Comblin la acción de la Iglesia es la evangelización de la cultura. Él sigue, en este aspecto al Concilio Vaticano II y Evangelii Nuntiandi. Pero es crítico con respecto al modo en que la Iglesia ha evangelizado a lo largo de la historia latinoamericana. La evangelización consistía en una acción que se dirigía a la mente del hombre. Se trataba de dar nuevas ideas. Comblin valora el cambio que realiza el Concilio hacia una concepción histórica del hombre. El hombre y su cultura no son solo ideas, sino que son historia, el hombre crea cultura en su historia. Comblin desarrolla su reflexión relacionando la evangelización con la liberación. Evangelizar la cultura es también liberarla: «La evangelización es una palabra, un mensaje para una cultura cuyo desafío es una liberación» (Comblin, 1988: 154). La evangelización debe incluir un mensaje sobre la 
liberación de la cultura que predomina actualmente. Pero ¿en qué consiste esta liberación?: consiste en el cambio de rumbo por el que naciones enteras pasan de la condición de periferia a la condición de centro productor de cultura (Comblin, 1988: 154). Este cambio de rumbo no solo es tarea y desafío de los pobres, sino también de ricos y dominantes:

Tanto las culturas en conserva, las culturas marginadas, como las culturas de las clases dominantes necesitan una liberación No solamente los pobres, sino los ricos también necesitan ser liberados o liberarse. Los pobres necesitan entrar en una cultura activa, auténtica, una cultura basada en un trabajo eficiente que los haga progresar realmente, una cultura que se produce y no que se transforma en símbolos de auto defensa. Los ricos necesitan ser liberados de una cultura vana, sin objeto, que deja puras frustraciones porque no lleva a ningún lugar (Comblin, 1988: 154).

Scannone plantea la acción de la Iglesia ante el desafío de la cultura latinoamericana desde otro punto de partida. No desde una situación distorsionada de culturas yuxtapuestas, sino desde la existencia de un núcleo cultural ético sapiencial que no solamente es objeto de evangelización, sino que es una forma con la cual se evangeliza el pueblo. Ese núcleo cultural, expresado en la religiosidad popular sigue continuamente evangelizando (Scannone, 1990: 131).

En esta línea, el desafío que se presenta hoy frente a la civilización técnica debe llevarse a cabo, según nuestro autor, mediante un nuevo esfuerzo de síntesis vital a partir de ese catolicismo popular latinoamericano. En este sentido afirma:

la sabiduría cristiana inculturada en la religiosidad popular latinoamericana puede ser punto de partida de una nueva síntesis vital que responda a la vocación que para Pablo VI — citado por Medellín y Puebla - tiene América latina, a saber, "aunar en una síntesis nueva y genial lo antiguo y lo moderno, lo espiritual y lo temporal, lo que otros nos entregaron y nuestra propia originalidad" [DP4] (Scannone, 1990: 137).

Pedro Trigo tiene como punto de partida la realidad multiétnica y pluricultural, frente a la cual el desafío que se presenta a los cristianos es doble: la inculturación de la fe en cada una de las culturas y el apoyo al reconocimiento a la diversidad cultural y étnica latinoamericana. Ahora bien, tal inculturación puede hacerse solo desde dentro de cada cultura, dando la «libertad a esas personas para que expresen su fe desde sí mismas» (Trigo, 2013: 317). Solo con estas condiciones se podrá realizar la inculturación. Ahora bien, quien realice la inculturación no podrá ser la institución de la Iglesia: 
la institución eclesiástica criolla está incapacitada para inculturar el cristianismo en las culturas indígenas, afrolatinoamericana, campesina y suburbana. La función que desempeña no la capacita para ello. Eso no se puede hacer desde departamentos criollos de conferencias episcopales criollas al servicio de los católicos de las demás culturas (Trigo, 2013: 317)

Paralelamente a esta inculturación múltiple, Trigo sostiene que se nos pide, como cristianos, «convertirnos a los de etnia y cultura no occidental» (Trigo, 2013: 315). Este reconocimiento de la condición multiétnica y pluricultural debe ser visto por los cristianos como una auténtica buena nueva y ocasión de salvación (Trigo, 2013: 315-316).

Con lo dicho podemos constatar que en los tres autores analizados existen más diferencias que convergencias respecto al tema tratado, tanto en lo referente al concepto mismo de cultura, como a la unidad cultural latinoamericana y la acción de la Iglesia. Estas diferencias no tienen solo que ver con lo conceptual, sino que implican también diversas prácticas pastorales. Las tres perspectivas suponen puntos de partida diferentes para la acción eclesial pastoral y se dirigen a distintos puntos de llegada. Se puede decir, a grosso modo, que en el escrito de Comblin se busca la liberación cultural, Scannone propone una nueva síntesis a partir del sustrato católico popular, y Trigo persigue la inculturación del evangelio en cada una de las etnias y culturas de nuestro subcontinente, pero desde dentro de la cultura, no desde la institución eclesial.

Se puede constatar, también, un acentuado cambio en el vocabulario y el contenido de las reflexiones entre Trigo, por un lado, y Comblin y Scannone, considerando una distancia de más de veinte años entre los textos. En las reflexiones de Trigo se aprecia una suerte de distanciamiento con respecto a las categorías utilizadas en el Concilio Vaticano II, Evangelii Nuntiandi y las Conferencias Episcopales latinoamericanas hasta Santo Domingo. Ya no se encuentran los términos Evangelización, religiosidad popular o catolicismo popular; en cambio se habla de lo multiétnico y pluricultural. Esto refleja el cambio epocal al que hace referencia la Conferencia de Aparecida (CELAM, 2007).

\section{Conclusión}

Del análisis de los tres autores estudiados se puede concluir que sus diferencias son más marcadas que sus semejanzas. Las concepciones de la cultura y las relaciones con la fe cristiana, desarrolladas por estos autores son muchas veces no solo diferentes, sino opuestas. Por ejemplo la valoración positiva del sustrato cultural producto de la evangelización cultural hispana, tal como la encontramos en los escritos de Scannone, se 
opone a la crítica negativa del proceso evangelizador que encontramos en las reflexiones de Comblin; y la valoración positiva de lo multiétnico y pluricultural se opone, de alguna manera, a la valoración positiva de la unidad en el sustrato cultural católico latinoamericano tal como lo aprecia Scannone. No se percibe, entonces, una reflexión latinoamericana común con respecto a la relación fe y cultura. Ha faltado, creo yo, un trabajo de discusión y maduración en esta temática en la teología latinoamericana.

Ahora bien, esta investigación no tuvo como propósito explicar las causas de las similitudes y diferencias en las reflexiones sobre la relación entre fe y cultura. Sin embargo se pueden aventurar algunas hipótesis al respecto. Las marcadas diferencias se pueden deber, en gran medida, no solo a la distancia temporal entre los escritos, sino también la distancia geográfica, y, justamente, cultural. Pues, a pesar de lo común de la realidad latinoamericana en general, las realidades socioculturales de sus diversos países son marcadas. Las realidades de Venezuela, Brasil y Argentina - los tres países de origen de los autores estudiados- son diferentes, y estas diferencias pueden haber influido a las reflexiones teológicas. Por otro lado, la complejidad del tema condiciona una aproximación hermenéutica también compleja. Las perspectivas desde donde se aproximan los teólogos al tema en cuestión provienen de distintas matrices sociológicas, ideológicas o antropológicas. Esta diversidad de perspectivas condiciona las distintas concepciones de cultura y las distintas conclusiones teológico-pastorales. Por último, también influyen los distintos momentos culturales en que se escribieron los artículos analizados. Las reflexiones de Pedro Trigo reflejan preocupaciones y maneras de ver la sociedad y su cultura muy distintas a las de los años 70 y 80 . Pues obviamente los teólogos reflejan también los distintos momentos culturales y sociales.

Creo necesario reconocer, finalmente, los serios esfuerzos que han realizado varios de los teólogos latinoamericanos por reflexionar la cultura y su relación con la fe. Es necesario continuar con este esfuerzo, ahora frente a los retos que nos plantea el horizonte cultural actual. En este sentido, me inclino por la opción presentada por J.C. Scannone, enfocada hacia la elaboración de nuevas síntesis culturales que puedan hacer frente a los desafíos que nos presenta la globalización cultural, desde el sustrato cultural evangelizado propio del pueblo latinoamericano.

\section{REFERENCIAS}

-CELAM (1971). Iglesia y liberación bumana: los documentos de Medellín. Santiago: Editorial Salesiana. 
-CELAM (1985). Puebla. La evangelización en el presente y en el futuro de América Latina (Quinta Edición). Bogotá: Ediciones CELAM.

-CELAM (2007). Aparecida. Documento Conclusivo. Santiago: Salesianos Impresores.

-Comblin, J. (1988). Evangelización de la cultura en América Latina. Persona y Sociedad, 2, 139-154.

-Concilio Vaticano II (1966). Documentos. Madrid: BAC.

-Fornet-Betancourt, R. (2007). Interculturalidad y Religión Para una lectura intercultural de la crisis actual del cristianismo. Quito: Abya-Yala.

-Gaudium et Spes (1966). En Concilio Vaticano II, Documentos. Madrid: BAC.

-Gutiérrez, G. (1988). Teología de la Liberación. Perspectivas. Lima: CEP.

-Irarrázabal, D. (2013). Indagación cristiana en los márgenes. Un clamor latinoamericano. Santiago: Ediciones Alberto Hurtado.

-Muñoz, R. (2009). Nueva conciencia cristiana en un mundo globalizado. Santiago: LOM.

-Pablo VI (1995). Evangelii Nuntiandi. Santiago: San Pablo.

-Roldán, A. (2000). La Iglesia frente al desafío de la posmodernidad y el pluralismo. Cuadernos de teología, XX, 213-230.

-Scannone, J. C. (1990). Evangelización, Cultura y Teología. Buenos Aires: Guadalupe.

-Scannone, J. C. (2012). Aportaciones de la teología argentina del pueblo a la teología Latinoamericana. En S. Torres, \& C. Ábrigo (Eds.), Actualidady vigencia de la teología Latinoamericana, Renovación y proyección (pp. 203-225). Santiago: Ediciones Universidad Católica Silva Henríquez.

-Silva, S. (1992). Desafíos y problemas de método. Una perspectiva latinoamericana. Teología y Vida, XXXII(I), 53-77.

-Toland, E. (2013). La misión cristiana y la cultura postmoderna. Recuperado de

http:/www.amerindiaenlared.org/upload/libros/1379352843_attach78.doc $\mathrm{x}$

-Trigo, P. (2013). Relaciones Humanizadoras. Un imaginario alternativo. Santiago: Ediciones Universidad Alberto Hurtado.

-Vasilachis de Giandino, I. (Ed.) (2006). Estrategias de investigación cualitativa. Barcelona: Gedisa.

Sumario: Introducción; 1. Análisis de texto; 1.1. Joseph Comblin, "Evangelización de la cultura en América Latina"; 1.2. Juan Carlos Scannone: "Ethos y sociedad en América latina: perspectivas sistemático-pastorales" y "Evangelización de la cultura y religiosidad popular latinoamericana"; 1.3. Pedro Trigo, "Construir una América Latina pluricultural para contribuir proactivamente a una mundialización alternativa"; 2. Análisis comporativo; 2.1. Convergencias; 2.2. Diferencias; 2.2.1. Concepto de cultura; 2.2.2. Unidad cultural; 2.2.3. La acción de la Iglesia; Conclusión; Referencias. 